\title{
DYNAMIC FIELD TESTS AND STUDIES ON VIBRATIONAL CHARACTERISTICS OF LONG-SPAN SUSPENSION BRIDGES
}

\author{
Isao OKAUCHI*, Toshio MIYATA**, \\ Masaaki TATSUMI*** \\ and Renji KIYOTA****
}

\begin{abstract}
To evaluate the wind resistance of suspension bridge, it would be necessary to know the vibrational characteristics, such as natural frequency, mode shape and structural damping, of actual bridge.

Some dynamic field tests using two special vibrators were conducted at the Ohnaruto Bridge, the Ohshima Bridge and the Minami Bisan-Seto Bridge.

At the tests, the vibration of large amplitude was excited,and some interesting vibrational properties as regards natural frequencies and damping values were obtained.

This paper describes the test results and some studies.

Keywords : vibrational characteristic, vibration test, suspension bridge
\end{abstract}

\section{INTRODUCTION}

Suspension bridges exhibit considerable flexibility,so that their wind resistance must be sufficiently verified. For the Honshu-Shikoku bridges, design code requirement for the wind resistance ${ }^{1)}$ had been prepared, and it was required to verify aerodynamic stability by conducting wind tunnel model tests. To evaluate the resistance to wind, it is necessary to fully understand the vibrational characteristics of an actual bridge.

For the analysis of natural vibration, a structural system is modeled for convenience of calculations. Therefore, it is necessary to fully grasp the influence by modeling a structural system in the calculation results.

Moreover, although the damping of the structural system is particularly important in the verification of aerodynamic stability, it is theoretically difficult to estimate it quantitatively. It is therefore important to measure the damping of actual structures and to accumulate the measured data. When we examine those existing data on suspension bridges, it is, found that in most cases, the vibration damping data on suspension bridges has been obtained from only the ambient vibration but not from its free vibration. In addition, the amplitude excited under free vibration in a few test is usually small and does not satisfy the amplitude

* Member of JSCE, D. Eng., Professor,Department of Civil Engineering, Chuo University

(Kasuga 1-13-27, Bunkyo-ku, Tokyo 112)

** Member of JSCE, D. Eng., Professor,Department of Civil Engineering, Yokohama National University

*** Member of JSCE, M. Eng., Tarumi Construction Office, Honshu-Shikoku Bridge Authority

**** Member of JSCE, M. Eng., Research Institute, Yokogawa Bridge Corporation. code large enough for evaluating structural damping, which are specified in the "Wind tunnel test manual for Honshu-Shikoku bridges"2).

Then, Honshu-Shikoku Bridge Authority developed a special large-scale vibrator that can excite lower frequencies in order to fully understand the vibrational characteristics of long-span suspension bridges, and carried out a couple of field vibration tests with unprecedentedly large amplitude on the Ohnaruto Bridge, the Ohshima Bridge and the Minami Bisan-Seto Bridge.

This paper describes the test results and studies on these bridges.

\section{OUTLINE OF VIBRATION TESTS}

\section{(1) Bridges Subjected to Tests}

For the test and analyses, three bridges were selected. Table 2.1 schematizes the outline of these bridges.

\section{( 2 ) Test Equipment}

a) Vibrator

Vibrator used for the tests was the crank type which incorporate a mechanism that lifts or lowers the weight with an electric motor and thereby applies vertical repeated force (exciting force) to the bridge body. The application of this exciting force can be stopped instantaneously and is thus very effective for obtaining free vibration. The exciting frequency range and maximum exciting force were 0.1 to $2.0 \mathrm{~Hz}$ and $200 \mathrm{kN}(0.5 \mathrm{~Hz})$, respectively. The total weight of a vibrator is about $840 \mathrm{kN}$. Photo. 2.1 shows the arrangement of vibrators on the Ohnaruto Bridge.

\section{b) Measuring instruments}

Fig.2.1 shows the location of the measuring instruments installed on the Ohshima Bridge. Basically, similar measuring instruments were 
Table 2.1 Test bridges

\begin{tabular}{|c|c|c|c|c|}
\hline $\begin{array}{l}\text { Bridge name } \\
\text { (route name) }\end{array}$ & $\begin{array}{l}\text { Suspended } \\
\text { structure }\end{array}$ & $S$ p a $n(m)$ & $\begin{array}{l}\text { Cross-section of } \\
\text { stiffening girder }(m)\end{array}$ & Remarks \\
\hline $\begin{array}{l}\text { Minami Bisan- } \\
\text { Seto Br idge } \\
\text { (Ko jima } \\
\text {-Sakaide) }\end{array}$ & $\begin{array}{l}3 \text {-span } \\
\text { continuous } \\
\text { stiffening } \\
\text { truss }\end{array}$ & 274 & 30. & $\begin{array}{l}\text { Dead weight } 441 \mathrm{KN} / \mathrm{m} \\
\text { (Stiffening girder } \\
314 \mathrm{KN} / \mathrm{m} \text { ) } \\
\text { Basic wind velocity } 43 \mathrm{~m} / \mathrm{s} \\
\text { Highway/Railroad bridge } \\
\text { Bridge axial azimuth } \\
\text { N-S }\end{array}$ \\
\hline $\begin{array}{l}\text { Ohnaruto } \\
\text { Bridge } \\
\text { (Kobe } \\
\quad \text {-Naruto) }\end{array}$ & $\begin{array}{l}\text { 3-Span 2-hinge } \\
\text { stiffening } \\
\text { truss }\end{array}$ & $=$ & 34 & $\begin{array}{l}\text { Dead weight } 314 \mathrm{KN} / \mathrm{m} \\
\text { (Stiffening girder } \\
235 \mathrm{KN} / \mathrm{m} \text { ) } \\
\text { Basic wind velocity } 50 \mathrm{~m} / \mathrm{s} \\
\text { Highway/Railroad bridge } \\
\text { Bridge axial azimuth } \\
\text { ENE-WSW }\end{array}$ \\
\hline $\begin{array}{l}\text { Ohsima } \\
\text { Bridge } \\
\text { (Onomichi } \\
\text {-Imabari) }\end{array}$ & $\begin{array}{l}\text { 1-Span } \\
\text { stiffening } \\
\text { box girder }\end{array}$ & 140 & $\frac{\sim}{23.7}$ & $\begin{array}{l}\text { Dead weight } 147 \mathrm{KN} / \mathrm{m} \\
\text { (Stiffening girder } \\
\text { Basic wind velocity } 37 \mathrm{mN} / \mathrm{s} \\
\text { Highway bridge } \\
\text { Bridge axial azimuth } \\
\text { NNW-SSE }\end{array}$ \\
\hline
\end{tabular}

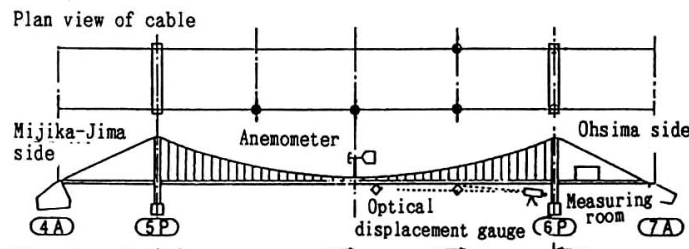

Plan view of girder

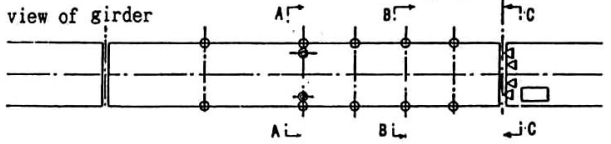

\begin{tabular}{|c|l|}
\hline B己 & Heasuring instrument \\
\hline$>$ & Optical displacement gauge $(\mathrm{L} / \mathbf{2}, \mathrm{L} / \mathbf{4})$ \\
\hline$\bigcirc$ & Accelemoneter (vertical) \\
\hline$\bigcirc$ & Accelemoneter (lateral) \\
\hline O & Accelemoneter (longi tudinal) \\
\hline$\triangleleft$ & Displacenent gauge (long itudinal) \\
\hline
\end{tabular}

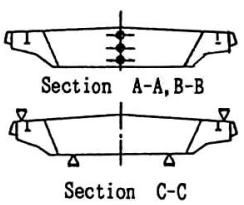

Fig.2.1 Location of measuring instruments (Ohshima Bridge)

arranged on all three bridges. All measured data were stored on magnetic tapes, and processed temporarity by a waveform processing unit or personal computer so that the results could be monitored. To verify the displacement which is calculated from the acceleration data, non-contact type optical displacement gauges were also installed.

To understand the vibrational characteristics, each acceleration of the stiffening girder in the vertical, lateral and longitudinal directions, acceleration of the cable in the lateral directions, and longitudinal displacement at the girder end, were measured. In addition, the direction and velocity of the wind at the center of the girder and the temperatures at the girder and road surface were measured for reference.

\section{( 3 ) Test Procedure}

The test was conducted as follows.

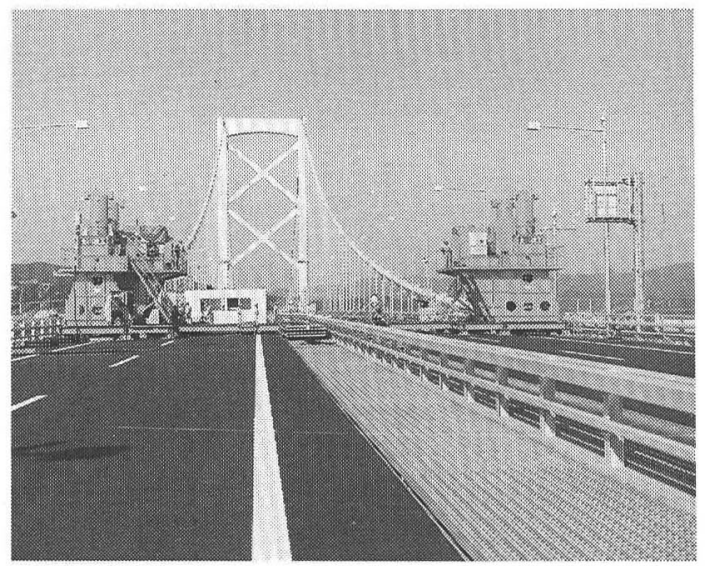

Photo 2.1 Vibrators installed on the Ohnaruto Bridge

(1) Ambient vibration measurement ; Ambient vibrations were measured, and the dominant frequency was estimated by spectral analysis.

(2) Forced vibration test ; The bridge was excited with the dominant frequency and frequencies close to it, and the resonance frequency was obtained from the vibrational responses.

(3) Free vibration test; The bridge was excited with the resonance frequency, and exciting was abruptly stopped when the amplitude became stationary, then the free vibration was measured.

\section{ANALYSIS OF NATURAL VIBRATION}

When analyzing the natural vibration, a structural system is modeled by simplifying the actual structure. The calculated results are largely influenced by analytical model used. To evaluate the results of analysis, therefore, it is important to understand the influence of modeling. Here we studied the influence of the torsional rigidity of a truss structure, the rigidity of a floor structure, and 
the boundary conditions of a stiffening girder, all of which were considered influential factors when modeling the stiffening truss with a single beam. The structural system was modelled a multi-lumped mass, a space frame model in which the stiffening girder was replaced with a single beam, and the initial force of the members (initial rigidity) and the restoring effect of the dead weight (gravitational rigidity $^{3}$ ) due to torsional deformation of the stiffening girder were considered. The program used for the analysis is SAP-IV.

a) Torsional rigidity of stiffening truss

Generally, the theory ${ }^{4,5}$ proposed by Komatsu or Bleich is used to calculate the torsional rigidity of a truss structure. Comparisons of the torsional rigidity between arithmetic expressions by Komatsu and Bleich and that of the space frame structure are as shown in Table 3.1. The torsional rigidity of a space frame structure was calculated as the rigidity of an equivalent beam in which the deformation is equal to that of the cantilever truss. In the Ohnaruto Bridge and the Minami Bisan-Seto Bridge, the torsional rigidity by the Bleich conversion formula was evaluated as 11 to $39 \%$ larger than by the Komatsu formula. The rigidity obtained by analyzing the space frame structure at the center cross section of the Ohnaruto Bridge approximated that obtained with the Komatsu expression.

b) Rigidity of floor structure

The road floor structure (hereinafter called floor structure) of both the Ohnaruto Bridge and the Minami Bisan-Seto Bridge consists of a steel plate girder of four to six continuous spans with an orthotropic steel deck. From the design aspect, this structure is considered not to restrain the deformation of the main girder, and is not evaluated as the cross section of the stiffening truss. However, it is assumed that the actual structure restrains the deformation of the stiffening girder if it is small, thus contributing to the rigidity of the truss. The influence of restrain has been therefore compared using the following models.

(1) The floor structure is composited with the main structure (composited).

(2) The floor structure and the main structure have independent cross-section rigidities (noncomposited).

(3) The floor structure does not contribute to the rigidity of the main structure (floor ignored).

The rigidities of the girder cross section obtained with comparative models are as shown in Table 3.2. There is almost no difference between the rigidity of the ignored model and that of the noncomposited one in the two bridges; however, the rigidity of the composited model is greater than
Table 3.1 Torsional rigidities of truss obtained with different arithmetic expressions

\begin{tabular}{|c|c|c|c|c|}
\hline Bridge name & (1) Space frame & (2)Breich exp. & (3)Komatsu exp. & (2) $/(3)$ \\
\hline $\begin{array}{c}\text { Ohnaruto Bridge } \\
\text { General } \\
\text { cross-section } \\
\text { Center } \\
\text { cross-section }\end{array}$ & $\begin{array}{c}9.14 \\
(1.00)\end{array}$ & 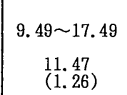 & $\begin{array}{l}7.91 \sim 12.58 \\
9.22 \\
(1.01)\end{array}$ & $\begin{array}{c}1.11 \sim 1.39 \\
1.24\end{array}$ \\
\hline Minami Bisan-Seto & & $17.74 \sim 34.99$ & $14.61 \sim 25.48$ & $1.21 \sim 1.37$ \\
\hline
\end{tabular}

Note:Figures in parenthesis are ratio for the space frame structure analys is

Table 3.2 Comparison of the girder rigidities by evaluating of the floor structure

\begin{tabular}{|c|c|c|c|}
\hline \multirow[t]{2}{*}{ Bridge name } & \multirow[t]{2}{*}{ mode } & \multicolumn{2}{|c|}{ Ratio of rigidity } \\
\hline & & $\frac{\text { non-composited }}{\text { floor ignored }}$ & $\begin{array}{l}\text { composited } \\
\text { floor ignored }\end{array}$ \\
\hline Ohnaruto Bridge & Torsional & 1.00 & $1.40 \sim 1.63$ \\
\hline & $\begin{array}{l}\text { Vertical } \\
\text { Lateral }\end{array}$ & $\begin{array}{l}1.00 \\
1.04\end{array}$ & $\begin{array}{l}1.69 \sim 1.80 \\
1.20 \sim 1.23\end{array}$ \\
\hline Minami Bisan-Seto & Torsional & 1.00 & $1.18 \sim 1.31$ \\
\hline & $\begin{array}{l}\text { Vertical } \\
\text { Lateral }\end{array}$ & $\begin{array}{l}1.00 \sim 1.00 \\
1.01 \sim 1.00\end{array}$ & $\begin{array}{l}1.23 \sim 1.76 \\
1.05 \sim 1.16\end{array}$ \\
\hline
\end{tabular}

that of the other model.

c) Boundary conditions of stiffening girder

The supporting point of stiffening girder of a suspension bridge is structurally free in the longitudinal direction ; however, it is assumed that, in actuality, the supporting point is subjected to some restraint. Thus we studied the differences when the girder supporting point was free in the longitudinal direction and when it was restrained.

\section{VIBRATIONAL CHARACTERISTICS OF ACTUAL BRIDGES}

\section{(1) Mode Shapes of Natural Vibration}

Fig.4.1 shows lower-order mode shapes there bridge. The calculated modes of vibration disregarded the rigidity of the floor structure, and the Komatsu expression was used to calculate torsional rigidity. The measured mode shape were obtained from the acceleration amplitude. The calculated mode shape of the stiffening girder corresponded well to the measured mode of vibration, but the calculated mode shape of the cable during the torsional vibration did not always correspond to the measured mode one.

a) Mode shapes of torsional vibration

In the first symmetric tortional mode shapes of the Ohnaruto Bridge and the Minami Bisan-Seto Bridge, two natural modes of similar mode shape having near-by natural frequency that were coupled with lateral vibraiton were obtained by calculation. Fig.4.1 shows the calculated mode shapes that correspond to the measured one. In the Ohnaruto Bridge, only the first symmetric tortional mode which couples largely with lateral vibration was observed. In this mode, the cable was largely 
(Minami Bisann-Seto Bridge)

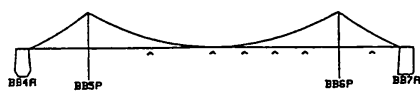

[1st sym, vertical mode]

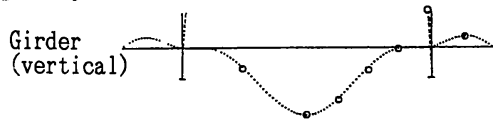

[1st asym. vertical mode]

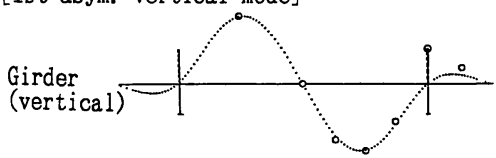

[1st sym, torsional mode]

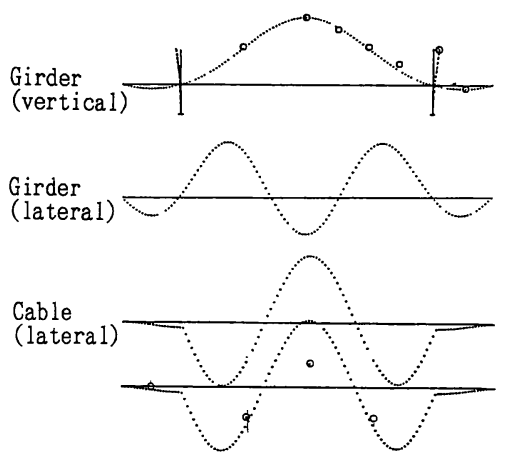

[1st asym. torsional mode]
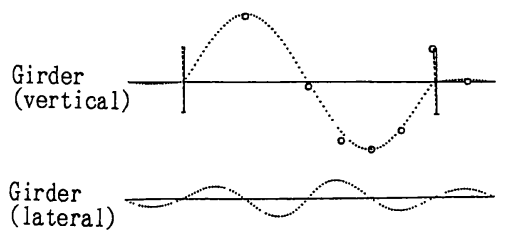

Cable

(latera1)

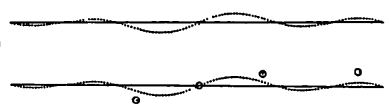

(Ohnaruto Bridge)
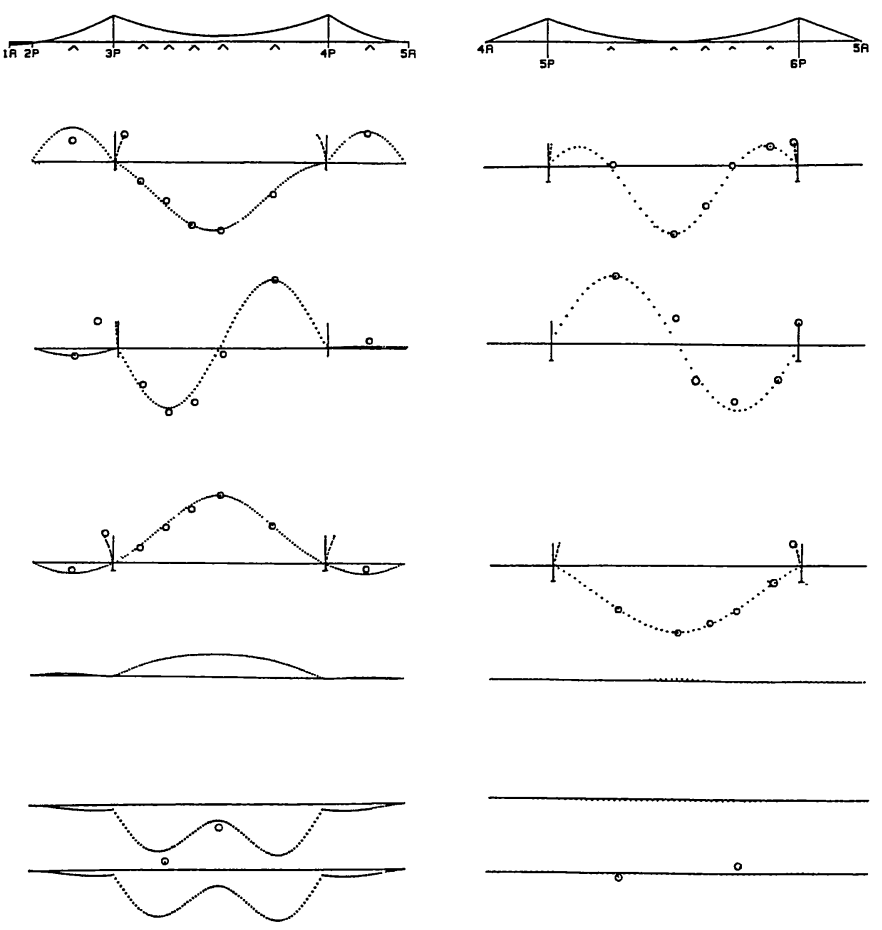

(Ohsima Bridge)
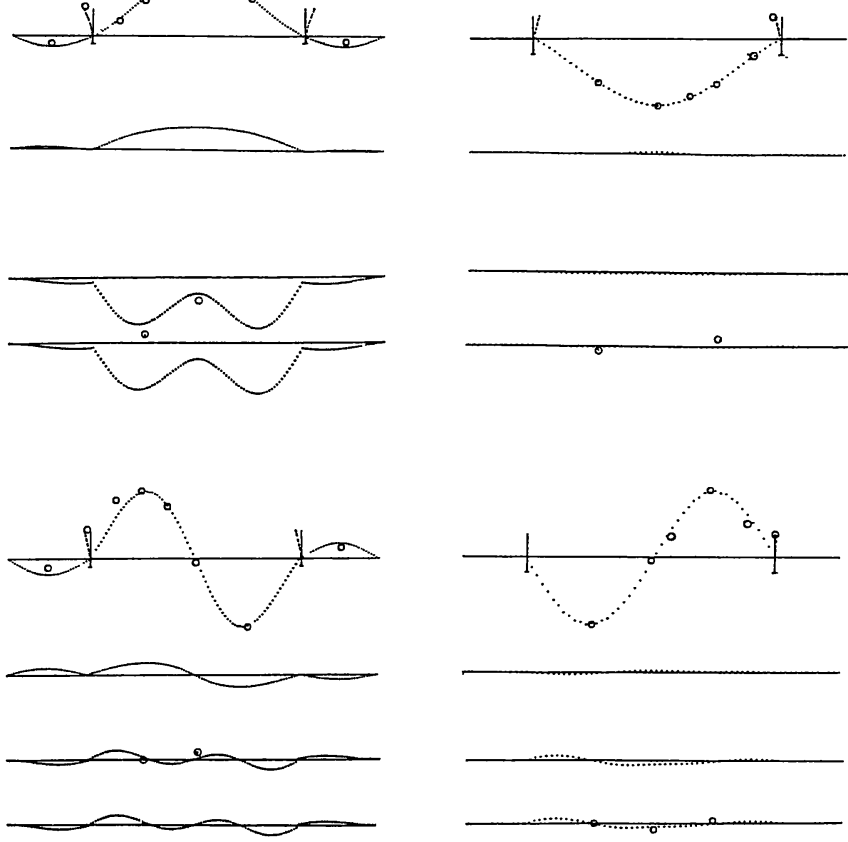

Fig.4.1 Lower-order mode shapes of three bridge

excited laterally, and the torsional mortion of the girder had a beat phenomenon which is considered attributable to coupled vibration. On the other hand, in the Minami Bisan-Seto Bridge, only the mode of torsional vibration coupled with small lateral vibration was observed. The contribution of the cable's lateral vibration for torsional mode is thus evaluated as very small in the Minami BisanSeto Bridge. In the Ohshima Bridge, the cable was not excited laterally when torsional vibration was applied.

b) Influence of boundary conditions at the girder end

In the Ohnaruto Bridge, the first asymmetric vertical mode which was under the steady-state vibration changed to the first symmetric vertical mode when the excitation was stopped and was placed under free vibration. This phenomenon seems to be attributable to the following mechanism. Stopping the excitation allows the longitudinal movement of the girder end to be restricted by friction. Since the natural frequencies of both modes were very close, the asymmetrical mode would be damped gradually. As a result, the vibration changed to the symmetrical mode which produces less longitudinal displacement.

In the case of the Ohshima Bridge, as shown in Table 4.1, the calculation (structural system without center cable stays) presents two vertical modes similar to the first asymmetric vertical one in which the displacement phase in the longitudinal direction differs between the-girder and the cable ; 
Table 4.1 Natural frequency of three bridges

Unit: $\mathrm{Hz}$

\begin{tabular}{|c|c|c|c|c|c|c|}
\hline & \multirow{2}{*}{$\begin{array}{l}\text { Vibrational mode } \\
\text { [with cable }(\mathrm{Y}) \\
\text { or not }(\mathrm{N})]\end{array}$} & \multicolumn{2}{|c|}{ Calculated value } & \multirow{2}{*}{$\begin{array}{l}\text { Resonance } \\
\text { frequency }\end{array}$} & \multirow{2}{*}{$\begin{array}{l}\text { Change of natural } \\
\text { frequency under } \\
\text { free vibration } \\
\text { [number of waves] }\end{array}$} & \multirow{2}{*}{$\begin{array}{l}\text { Dominant } \\
\text { frequency }\end{array}$} \\
\hline & & $\begin{array}{l}\text { Floor } \\
\text { ignored }\end{array}$ & $\begin{array}{l}\text { Floor } \\
\text { composited }\end{array}$ & & & \\
\hline \multirow{2}{*}{ 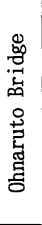 } & 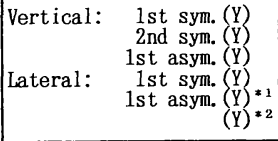 & $\begin{array}{l}0.154 \\
0.268 \\
0.149 \\
0.086 \\
0.273 \\
0.346\end{array}$ & $\begin{array}{l}0.164(1.06) \\
0.314(1.17) \\
0.167(1.12) \\
0.091(1.06) \\
0.285(1.04) \\
0.364(1.05)\end{array}$ & $\begin{array}{l}0.165(1.09) \\
0.284(1.06) \\
0.164(1.10)\end{array}$ & 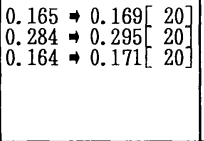 & $\begin{array}{l}0.173(1.14) \\
0.298(1.11) \\
0.172(1.15) \\
0.092(1.07) \\
0.276(1.01) \\
0.362(1.05\end{array}$ \\
\hline & 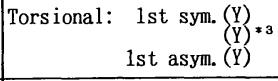 & $\begin{array}{l}0.333 \\
0.304 \\
0.457 \\
\end{array}$ & $\begin{array}{l}0.355(1.07) \\
0.349(1.15) \\
0.537(1.18)\end{array}$ & $\begin{array}{l}1.08) \\
1.11)\end{array}$ & {$\left[\begin{array}{l}0.328 \Rightarrow 0.332[120] \\
0.506 \Rightarrow 0.517\left[\begin{array}{r}20\end{array}\right]\end{array}\right]$} & $\begin{array}{l}0.334(1.08) \\
0.527(1.15)\end{array}$ \\
\hline \multirow{3}{*}{ 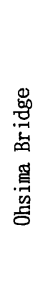 } & 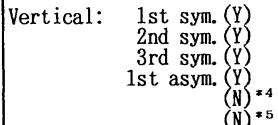 & \multirow{2}{*}{\multicolumn{2}{|c|}{$\begin{array}{l}0.232 \\
0.321 \\
0.541 \\
0.157 \\
0.137 \\
0.192 \\
0.717 \\
0.717 \\
0.128 \\
0.434\end{array}$}} & $\begin{array}{l}0.232(1.00) \\
0.323(1.01) \\
0.540(1.00) \\
0.189(1.20) \\
0.172(1.26)\end{array}$ & 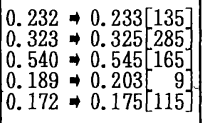 & $\begin{array}{l}0.232(1.00) \\
0.326(1.02) \\
0.551(1.02) \\
0.210(1.34) \\
0.178(1.30)\end{array}$ \\
\hline & 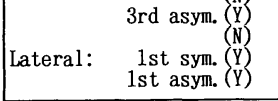 & & & $\begin{array}{l}0.711(0.99) \\
0.712(0.99)\end{array}$ & {$\left[\begin{array}{l}0.711 \Rightarrow 0.718[145] \\
0.712 \Rightarrow 0.720[125]\end{array}\right]$} & $\begin{array}{l}0.723(1.01) \\
0.726(1.01) \\
0.143(1.12) \\
0.449(1.03)\end{array}$ \\
\hline & Tors ional: $\begin{array}{r}\text { 1st sym. (Y) } \\
\text { 1st asym. (Y) }\end{array}$ & \multicolumn{2}{|l|}{$\begin{array}{l}0.541 \\
0.741 \\
0.717\end{array}$} & $\begin{array}{l}0.550 \sim 0.553 \\
0.744 \sim 0.774 \\
0.725 \sim 0.748\end{array}$ & 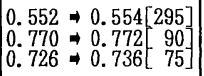 & $\begin{array}{l}0.557(1.03) \\
0.772(1.04) \\
0.747(1.04)\end{array}$ \\
\hline 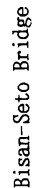 & \begin{tabular}{|lc} 
Vertical: & 1st sym. (Y) \\
& 2nd sym. (Y) \\
& 3rd sym. (Y) \\
& 4th sym. (Y) \\
& 1st asym. (Y) \\
1st sym. (Y) & 1 \\
Lateral: & 1st asym. (Y) \\
& \\
\end{tabular} & $\begin{array}{l}0.165 \\
0.215 \\
0.356 \\
0.455 \\
0.129 \\
0.078 \\
0.187 \\
0.274 \\
\end{array}$ & $\begin{array}{l}0.169(1.02) \\
0.234(1.09) \\
0.404(1.13) \\
0.529(1.16) \\
0.137(1.06) \\
0.080(1.03) \\
0.194(1.04) \\
0.276(1.01)\end{array}$ & $\begin{array}{l}0.168(1.02) \\
0.228(1.06) \\
0.387(1.09) \\
0.472(1.04) \\
0.151(1.17)\end{array}$ & 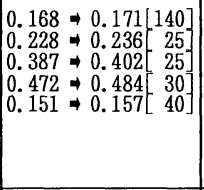 & $\begin{array}{l}0.171(1.04) \\
0.240(1.12) \\
0.420(1.18) \\
0.511(1.12) \\
0.160(1.24) \\
0.080(1.03) \\
0.194(1.04)\end{array}$ \\
\hline 焉 & 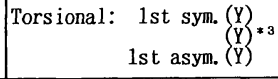 & $\begin{array}{l}0.310 \\
0.319 \\
0.431 \\
\end{array}$ & $\begin{array}{l}0.337(1.09) \\
0.325(1.03) \\
0.472(1.10)\end{array}$ & $\begin{array}{l}0.329(1.06) \\
0.457(1.06)\end{array}$ & $\left.\begin{array}{l}0.329 \rightarrow 0.331[210] \\
0.457 \rightarrow 0.469[110]\end{array}\right]$ & $\begin{array}{l}0.334(1.08) \\
0.473(1.10)\end{array}$ \\
\hline
\end{tabular}

Note 1. Torsional rigidity according to the Komatu expression.

2. $* 1(* 2)$ : Lateral displacements of the girder and cable is on the positive(negative)-phase.

$* 3$ : Coupled with lateral vibration.

(4) Longitudinal displacement of the girder and cable is on the positive(negative)-phase.

3. Figures in parentheses show the ratios for caluculating values(floor structure is ignored).

however, at the test, only the mode of positivephase was observed. According to the calculation, restraining the longitudinal movement of the girder end produces only one mode. Because the stiffening girder end of the actual bridge is subjected to substantial restraint, the other mode may be difficult to be excited.

\section{(2) Natural Frequency}

Natural frequency was estimated from the dominant frequency in the measurement of ambient vibration and the resonance frequency in the forced vibration tests. Table 4.1 compares the test results with the calculated natural frequencies for three bridges. In the case of suspension bridges with truss girder, the frequency generally increases in the order of the calculated value (a floor structure is ignored), resonance frequency, dominant frequency and the calculated value (a floor structure is composited). The calculation shows a couple of torsional mode shapes similar to that of the first symetric mode which are coupled with lateral vibration, while the forced vibration test excited only one of them. The resonance frequencies are 6 to $10 \%$ larger in the Ohnaruto Bridge, -1 to + $26 \%$ in the Ohshima Bridge, and 2 to $17 \%$ in the
Minami Bisan-Seto Bridge than respective calculated values (the floor structure in truss girder is ignored). In all bridges, the difference between the measured and calculated frequencies of the first asymmetric vertical mode differs considerably from that of other modes. In the case of the Ohshima Bridge with stiffening box girder, this phenomenon is remarkable.However, the difference between the measured and calculated frequencies in the other vertical and torsional modes is $1 \%$, indicating a very good correspondence,compared with the case of suspension bridges with stiffening truss. The dominant frequency is higher by 0 to $4 \%$ than the resonance frequency in all bridges.

a) Changes in frequency under free vibration

A bridge which is excited by the resonance frequency switches over to free vibration when excitation is abruptly stopped. An example of the changes in frequency under free vibration is shown in Table 4.1. The frequency gradually approaches the dominant frequency. The percentages of variation in the frequency of the Ohnaruto Bridge, the Ohshima Bridge and the Minami Bisan-Seto Bridge are 1 to $3 \%, 1$ to $2 \%$ and 1 to $4 \%$, respectively. These variations are considered attributable 

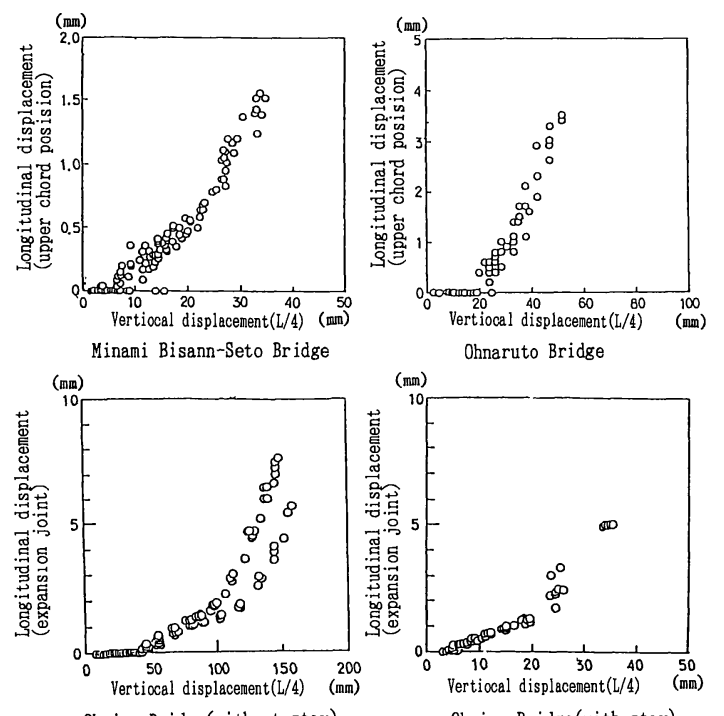

Ohsima Bridge(without stay)

Ohsima Bridge(with stay)

Fig.4.2 Relationship between vertical and longitudinal displacement(first asymmetric vertical mode)

to the contribution of the floor structure in the truss structure or a change in the boundary condition at the stiffening girder ends due to amplitude. In other words, it is assumed that the natural frequency of an actual bridge is dependent on the amplitude.

b) Influence of boundary conditions at the stiffening girder end

In the first asymmetric vertical mode compared with other modes, there is a substantial difference between the calculated value and the measured value in all bridges. This difference is particularly prominent in the Ohshima Bridge. Fig.4.2 shows the relationship between the maximum amplitude of the girder and the longitudinal displacement of the girder end under free vibration. In all bridges, the longitudinal displacement of the girder end is smaller than the calculated value, and it is almost undetectable under the small vibration. The first asymmetric vertical mode is accompanied by larger longitudinal movement of the stiffening girder, and is more influenced by the restraint at the girder end than any other modes.

Table 4.2 shows a comparison between calculated and measured frequency of the first asymmetric vertical mode when the longitudinal movement of the girder end is restrained. The calculated natural frequency when restrained is 11 to $37 \%$ larger than when not restrained. The dominant frequency is closer to the calculated frequency when the girder is restrained. The stiffening girder of the Ohshima Bridge is of a box girder and the floor structure is evaluated as the main struc-
Table 4.2 Influence of restraint at stiffening girder end on natural frequency (first asymmetric vertical mode)

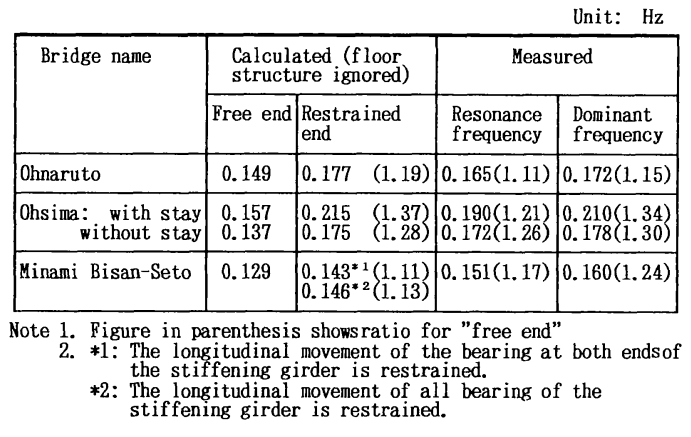

ture. Therefore, it is assumed that this is caused by the restraining of the girder end. In both the Ohnaruto Bridge and the Minami Bisan-Seto Bridge, the measured frequency is larger than the calculated one when the composition of the floor structure is considered, which suggests an influence when the girder end is restrained. It is assumed that the influence of restraining is prominent in the Ohshima Bridge because the weight of the suspended structure is light compared to the force of constraint. From a design viewpoint, the longitudinal movement of the bearing of a stiffening girder in a suspension bridge is made free. However, one can assume that in actual structures, boundary conditions are subject to restrictions at expansion joints or bearings and fluctuate according to amplitude in vibration. It seems that small vibration is more influenced by fluctuations in boundary conditions.

c) Contribution of floor structure to girder rigidity

When comparing the frequencies in the second symmetric vertical mode, which is least influenced by the restraint of the girder end, the measured value of the Ohnaruto Bridge is between the calculated values when the floor structure is situated neglected and composited ; the dominant frequency approximates the calculated value when the floor structure is composited ; and the resonance frequency is closer to the calculated value when the floor structure is neglected, as shown in Table 4.1. In the case of the Minami Bisan-Seto Bridge, the dominant frequency tends to be larger than the calculated value when the floor structure is composited. This is probably due to the fact that railroad girders or public extenders are not evaluated for rigidity of stiffening girder.

Fig.4.3 compares the natural frequencies in the first symmetric torsional mode. The relationship between measured and calculated valves is the same as that in the vertical mode. The contribution 


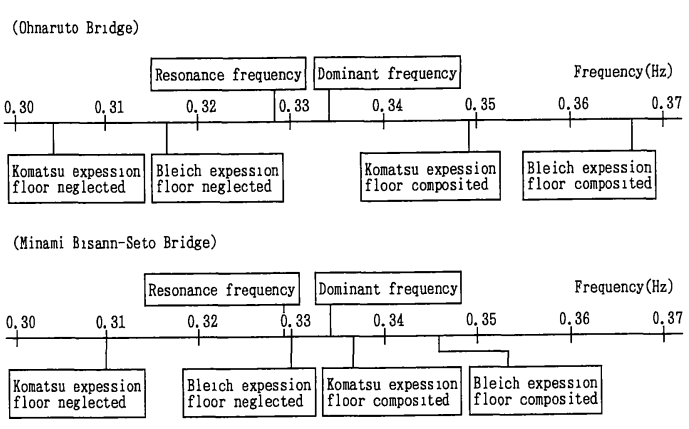

Fig.4.3 Comparison of natural frequencies (first symmetric torsional mode)

of the floor structure, however, cannot be specified because the methods of evaluating torsional rigidity are considered influential.

Fig.4.4 shows the measured deflection at the center of stiffening girder and the measured relative displacements in the longitudinal direction of floor structure and the main structure at the span center, when a nine-car train crosses over the Minami Bisan-Seto Bridge. The measured relative displacements of the both correspond to $1.35 \%$ of the deflection of the girder. Calculating the relative displacements of both accompanied by the girder's flexural deformation results in $1.34 \%$ of the deflection of the girder, which is in good agreement with the measured result. The floor structure is displaced relatively in the longitudinal direction, following the deflection of the girder. No compositional effect of the floor structure is recognized with respect to the train load.

d) Evaluation of torsional rigidity of stiffening truss

The torsional rigidity of a truss differs considerably according to how it is evaluated. As shown in Table 3.1, there is a difference of 10 to $40 \%$ between the calculated rigidity by the Komatsu expression and that by the Bleich expression. The calculated natural frequency in accordance with the Komatsu expression is 3 to $9 \%$ smaller than that in accordance with the Bleich expression.

e) Relation with natural environment

Under the first asymmetric mode of the Ohshima Bridge, a phenomenon was observed in which the resonance frequency differed depending on when the measurements were executed. The resonance frequency estimated from the response curve indicated a $1.6 \%$ increase as the temperature decreased by 7 to 10 degrees.

f) Effect of center cable stay

The effect of the center cable stay on the Ohshima Bridge was investigated. In accordance with the measurement, by installing a stay, the
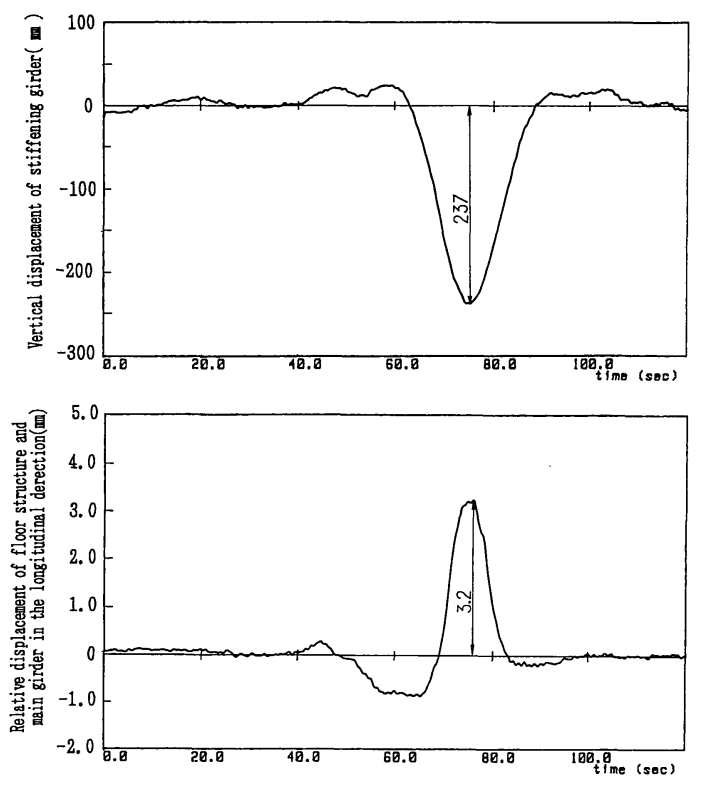

Fig.4.4 Displacement of stiffening girder and floor structure(Minami Bisan-Seto Bridge)

natural frequency increased by $15 \%$ and $3 \%$ in the first asymmetric vertical and torsional mode, respectively. The calculation also revealed an increase in natural frequency almost equal to $13 \%$ and $3 \%$ such as the measurement. The increase in rigidity under the first asymmetric vertical mode was remarkable.

\section{( 3 ) Structural Damping}

The reference amplitude for evaluating the structural damping is $1 / 200$ of the girder width in flexural vibration and 0.5 degrees in torsional vibration in accordance with the "Wind tunnel test manual for Honshu-Shikoku bridges (1980)". As a result of the test, the amplitude exceeding the required level could be excited in the Ohnaruto Bridge under the first symmetric torsional mode ; in the Ohshima Bridge under the first symmetric, second and third vertical modes, first asymmetric vertical mode (without stay) and the first symmetric and the first asymmetric torsional modes; and in the Minami Bisan-Seto Bridge under the first symmetric vertical mode. The measured structural damping of each bridge and the relationship between damping and amplitude in the major vibrational modes are shown in Table 4.3 and Fig.4.5, respectively. The damping was calculated as the logarithmic decrement from the peaks of vibratory wave per 2 to 10 waves. The logarithmic decrement of the Ohnaruto Bridge is as large as 0.066 to 0.12 in vertical vibration, while it decreased down to 0.028 to 0.050 in torsional vibration. In the Minami Bisan-Seto Bridge it is 
[1st sym. vertical mode]
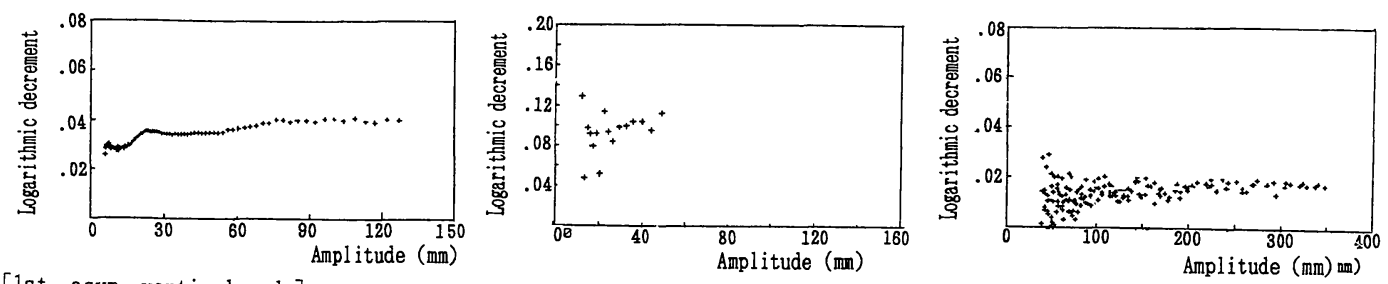

[1st asym. vertical mode]
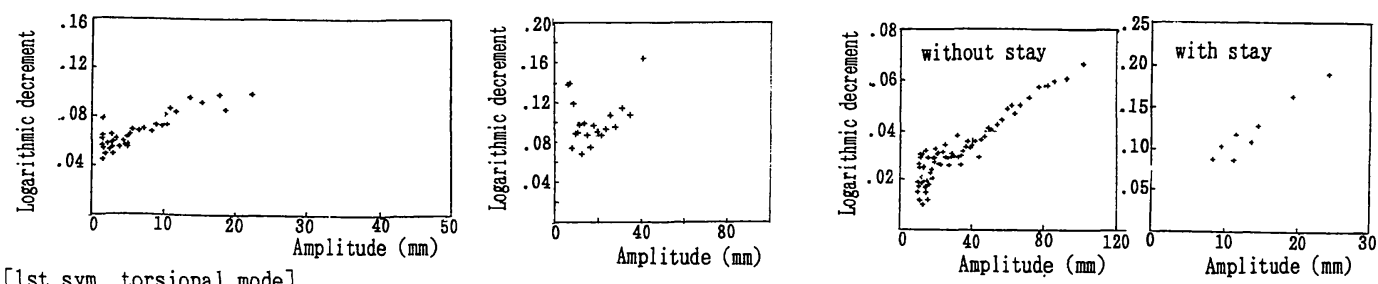

[1st sym. torsional mode]
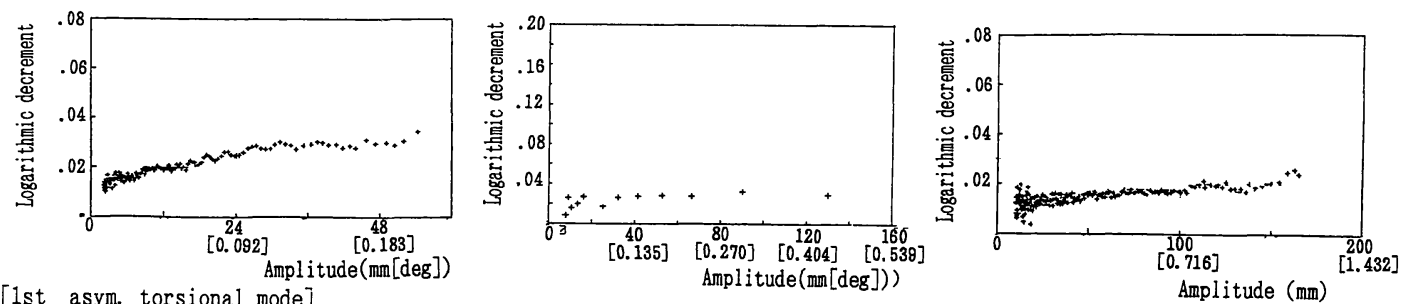

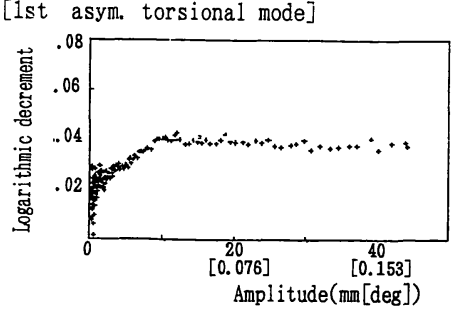

a. Minami Bisann-Seto Bridge

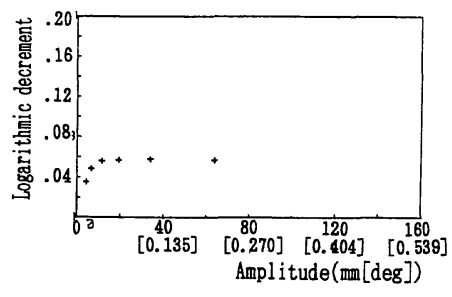

b. Ohnaruto $\mathrm{Bridge}$

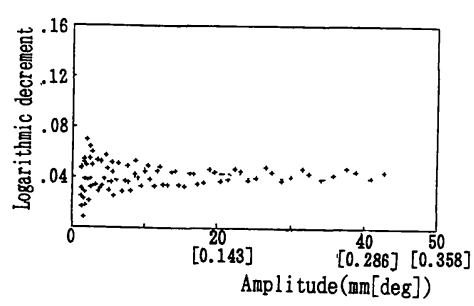

c. Ohs ima Bridge

Fig.4.5 Relationship between damping and amplitude

0.030 to 0.038 in torsional vibration, almost the same as that of the Ohnaruto Bridge. The logarithmic decrement in the first symmetric vertical mode of the same bridge, however, is as small as 0.040 , which differs from the case of the Ohnaruto Bridge. On the other hand. In the Ohshima bridge with a stiffening box girder, it is 0.015 to 0.019 and less than 0.02 , respectively, in the first and second symmetric vertical modes, and it increases as much as 0.16 in the first asymmetric vertical modes. The logarithmic decrement in the torsional vibration of the same bridge is 0.017 to 0.038 and does not reach even 0.020 in the first symmetric torsional mode.

a) Amplitude dependence of damping

i ) Ohnaruto Bridge

The logarithmic decrement in the first and second symmetric vertical modes is from 0.060 to 0.12 , showing a declining tendency in the small amplitude, and it tends to hold a constant value as the amplitude increases. In the first asymmetric vertical mode, the logarithmic decrement tends to increase as the amplitude increases, although the measured amplitude is limited within the small range.

The logarithmic decrement in the torsional mode tends to decrease in the small amplitude region, as it does in the vertical mode, and it becomes nearly constant as the amplitude increases.

\section{ii ) Ohshima Bridge}

The amplitude of free vibration, except for the first asymmetric vertical mode (with stay), have reached the required level. In the asymmetric vertical mode (with stay), the logarithmic decrement indicates a prominent amplitude dependence in which it increases as the amplitude increases, although the measured amplitude is within the small range. The first asymmetric vertical mode 
Table 4.3 Logarithmic decrement by free vibration test

\begin{tabular}{|c|c|c|c|c|c|}
\hline & $\begin{array}{l}\text { Vibrational mode } \\
{[\text { with stay }(Y)} \\
\text { or not }(N)]\end{array}$ & $\begin{array}{l}\text { Logar ithmic decre- } \\
\text { ment (ampl itude } \\
\text { evluated) }\end{array}$ & $\begin{array}{l}\text { Maximum ampl itude } \\
\text { mm[deg] }\end{array}$ & $\begin{array}{l}\text { Wind velocity } \\
\text { and direction } \\
(\mathrm{m} / \mathrm{s})\end{array}$ & $\begin{array}{l}\text { Temperature } \\
\text { in girder( } \\
\text { road surface) }\end{array}$ \\
\hline \multirow{2}{*}{ 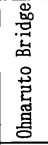 } & Vertical: $\begin{array}{r}\text { 1st sym. (Y) } \\
\text { 2nd sym. (Y) } \\
\text { 1st asym. (Y) }\end{array}$ & $\begin{array}{l}0.10-0.13 \text { (Max.) } \\
0.066-0.10 \text { (Max.) } \\
0.10-0.12 \text { (Max.) }\end{array}$ & $\begin{array}{l}49-70 \\
65-98 \\
26-57\end{array}$ & $\begin{array}{|ll|}6-9 & N E, S S E \\
2-10 & N N W, S-S W \\
1-6 & N W-N N W \\
\end{array}$ & $-\left[\begin{array}{l}- \\
- \\
-\end{array}\right]$ \\
\hline & $\begin{array}{c}\text { Torsional: 1st sym. (Y) } \\
1 \text { 1st asym. (Y) }\end{array}$ & $\begin{array}{l}0.028-0.041 \text { (Max.) } \\
0.050-0.057 \text { (Max.) }\end{array}$ & $\left.\begin{array}{r}126-176[0.41-0.57 \\
53-104[0.17-0.34\end{array}\right]$ & $\begin{array}{ll}6-9 & N-W \\
6-11 & \mathrm{~S}-\mathrm{SE} \\
\end{array}$ & $=[-]$ \\
\hline \multirow{2}{*}{ 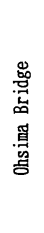 } & 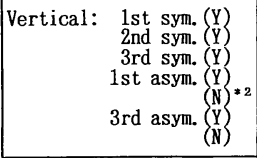 & $\begin{array}{l}0.015-0.030(\mathrm{~B} / 200) \\
0.019-0.050(\mathrm{~B} / 200) \\
0.028-0.030(\mathrm{~B} / 200) \\
0.16-0.23(\mathrm{~B} / 1200) \\
0.065-0.077(\mathrm{~B} / 200) \\
0.036-0.050(\mathrm{~B} / 400) \\
0.038-0.046(\mathrm{~B} / 400)\end{array}$ & $\begin{array}{r}216-367 \\
119-303 \\
216-367 \\
30-35 \\
146-162 \\
51-101 \\
92-100\end{array}$ & $\begin{array}{ll}2-12 & \mathrm{~W} \\
2-16 & \mathrm{~W}-\mathrm{NW}, \mathrm{SE} \\
3-10 & \mathrm{~W}-\mathrm{NW} \\
0-4 & \mathrm{~S}-\mathrm{E} \\
0-8 & \mathrm{E}-\mathrm{ENE} \\
0-10 & \mathrm{NE}, \mathrm{E}, \mathrm{S}-\mathrm{SE} \\
1-7 & \mathrm{E}-\mathrm{NE}, \mathrm{SE} \\
\end{array}$ & 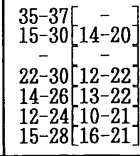 \\
\hline & $\begin{array}{r}\text { Torsional: } 1 \text { st sym. (Y) } \\
1 \text { st asym. (Y) } \\
\end{array}$ & $\begin{array}{l}0.017-0.035\left(0.5^{\circ}\right) \\
0.033-0.080\left(0.25^{\circ}\right) \\
0.038-0.071\left(0.25^{\circ}\right)\end{array}$ & $\left.\begin{array}{l}92-180[0.66-1.29] \\
34-70[0.25-0.50 \\
49-64[0.35-0.46]\end{array}\right]$ & 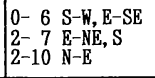 & 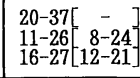 \\
\hline \multirow{2}{*}{ 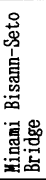 } & 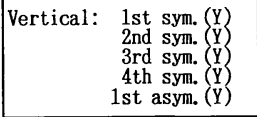 & $\begin{array}{l}0.040-0.055 \text { (Max.) } \\
0.096-0.10 \text { (Max. } \\
0.10-0.11 \text { (Max.) } \\
0.088-0.096 \text { (Max.) } \\
0.088-0.096 \text { (Max.) }\end{array}$ & $\begin{array}{c}124-164 \\
37-39 \\
23-24 \\
36-38 \\
34-37\end{array}$ & $\begin{array}{l}0-7 \text { ESE-E } \\
8-10 \text { WS-WSW } \\
0-13 \text { N,WNW } \\
1-6 \\
1-4 \text { WSW } \\
1-4 \text { W-SW }\end{array}$ & 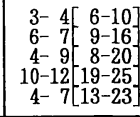 \\
\hline & 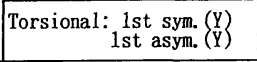 & $\begin{array}{l}0.030-0.044 \text { (Max.) } \\
0.038-0.044 \text { (Max. }\end{array}$ & $\left.\begin{array}{l}49-69[0.19-0.26 \\
49-61[0.19-0.23]\end{array}\right]$ & $\begin{array}{l}0-9 \\
1-12\end{array}$ SE-N, SW & $\begin{array}{l}1-10\left[\begin{array}{r}2-22 \\
4-7 \\
10-20\end{array}\right]\end{array}$ \\
\hline
\end{tabular}

intrinsically produces a large displacement in the longitudinal direction; however, the cable stay limits the longitudinal displacement of the girder and the cable and makes the vibration of both in the longitudinal direction on the positive-phase. Because of this, it is assumed that the cable stay increases the longitudinal displacement of the girder end which is under a semi-restrained state, thereby increasing the damping of the girder end by friction.

The logarithmic decrement in other modes decreases in small amplitudes, but it becomes nearly constant in the region of larger amplitudes. Thus no amplitude dependence is found in other modes.

\section{iii ) Minami Bisan-Seto Bridge}

In the first asymmetrical vertical mode, although limited to the micro-amplitude region, the logarithmic decrement increases as the amplitude increases, indicating the existence of amplitude dependence. The logarithmic decrement in other modes decreases in the small amplitude region, but it becomes almost constant in the larger amplitude region, indicating freedom from amplitude dependence.

b) Relationship between damping and natural environment

i) Influence of wind

Fig.4.6 shows a relationship between damping and changes in average wind velocity. The contribution of aerodynamic damping is estimated using the aerodynamic coefficient derived from wind tunnel tests, in the vertical mode of the Ohnaruto Bridge. The measured damping under

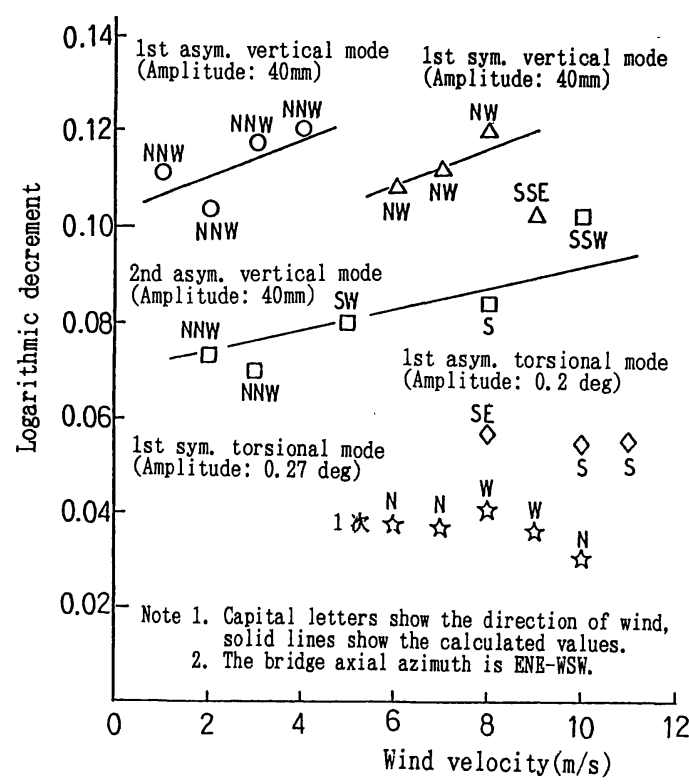

Fig.4.6 Relationship between damping and wind velocity (Ohnaruto Bridge)

approximate conditions generally revealed a close similarity to the calculated one.

ii) Influence of changes in temperature

The Ohshima Bridge presented a phenomenon in that the damping varied according to the time the tests were conducted. Fig.4.7 shows the relationship between the temperature and the logarithmic decrement in the torsional mode. When looking at the data under nearly constant wind velocity, the logarithmic decrement in the asymmetric torsional mode substantially decreased 

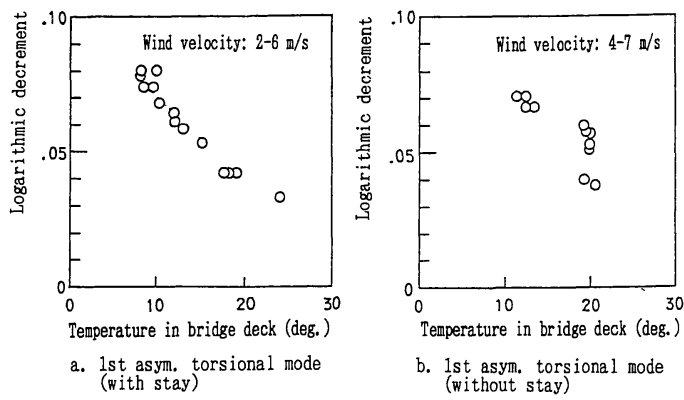

Fig.4.7 Relationship between damping and temperature (Ohshima Bridge)

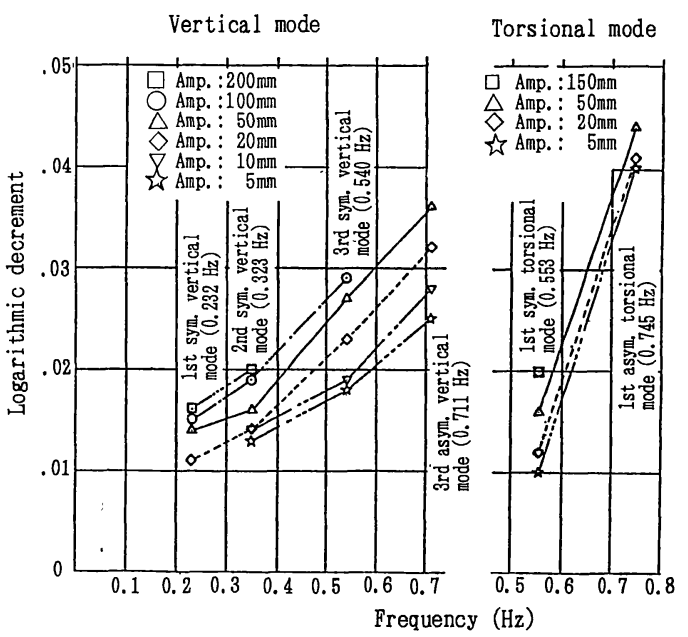

Fig.4.8 Relationship between damping value and vibrational modes (Ohshima Bridge)

from 0.08 to 0.03 when the temperature in the stiffening girder increased (10 to 15 degrees). There is a clear relationship between the logarithmic decrement and the temperature in the asymmetric torsional mode; however, such a clear relationship did not appear to exist with respect to other modes. This phenomenon found in the Ohshima Bridge is assumed to be attributable to the fact that its light-weight box girder is paved with asphalt which is strongly influenced by temperature.

The relationship between damping and temperature was not recognized in the Ohnaruto Bridge and the Minami Bisan-Seto Bridge.

c) Relation with modes of vibration

In the Ohshima Bridge, because tests for many modes were conducted, it is possible to evaluate the relation of the damping value to the modes of vibration. According to the available literature ${ }^{6,7)}$, the damping value obtained by ambient vibration measurement decreases at a higher mode of vibration. The results of the free vibration test, however, differ from those results. As shown in Fig.4.8, logarithmic decrements increased as the order of the mode of vibration increased in both vertical and torsional mode.

\section{(4) Center of Rotation of Stiffening Girder under Torsional Vibration}

The vibration of a stiffening girder subjected to torsional vibration can be considered as rotational motion around a certain point. The measured center of rotation at the peak point of the mode, under the torsional modes of vibration, was found at a position higher than the shear center. On the other hand, the center of rotation at the $\mathrm{L} / 4$ point in symmetrical modes of the Ohshima Bridge and the Minami Bisan-Seto Bridge were both found at a position below the shear center. The center of rotation thus differed according to the longitudinal position.

The center of rotation of an uniform simple been girder agrees with the center of twist under the mode of pure torsional vibration ; however, it does not agree with the center of twist under torsional vibration which is coupled with lateral vibration. As the mode of torsional vibration on actual suspension bridges accompanies by lateral vibration, the center of rotation of a stiffening girder generally changes according to the longitudinal position.

\section{CONCLUSIONS}

The results of the study can be summarized as follows.

(1) Natural vibrational characteristics

i) Mode shape of vibration

The measured mode shapes on stiffening girders nearly agree with the calculated ones.

ii ) Natural frequency

(1) Comparisons with analytical results

In the modes excluding the first asymmetric vertical mode, the measured natural frequencies of a suspension bridge with stiffening truss were higher by 2 to $9 \%$ than the calculated value, while the difference between two values was less than a mere $1 \%$ in the case of a suspension bridge with stiffening box girder. The measured resonance frequency in the first asymmetric vertical mode differed as much as 10 to $26 \%$ from the calculation in all bridges.

(2) Amplitude dependence

The resonance frequency is slightly smaller ( 0 to $4 \%$ ) than the dominant frequency under ambient vibration, and it approaches the dominant frequency when the vibrational state shifts from the resonant condition to free vibration. A dependence of the natural frequency on amplitude was found.

(3) Influence of restraint at the stiffening girder 
end

The girder end in an actual bridge is subject to restriction, increasing the natural frequency in the first asymmetric vertical mode which follows the longitudinal movement, in the same as a center cable stay.

(4) Influence of floor structure

The floor structure in a stiffening truss is assumed to contribute to the rigidity of a structural system under small vibration.

(5) Influence of temperature

In the case of the Ohshima Bridge, changes in resonance frequency that followed by changes in temperature under the first asymmetric vertical mode, was found.

6) Influence of center cable stay

A center cable stay restrains the relative displacement in the longitudinal direction of a girder and a cable, increases the rigidity of a structural system in the first asymmetrical modes of vertical and torsional vibration which accompanies the longitudinal displacement, and increases natural frequency.

iii) Structural damping

(1) General aspects

The logarithmic decrement in the torsional modes of the Ohnaruto Bridge with a two-hinge stiffening truss, was 0.028 to 0.050 , which is equivalent to or higher than the design standard $(\delta$ $=0.03$ ). However, the logarithmic decrement in all of the vertical modes was significantly larger, being 0.080 to 0.11 . In the case of the Minami Bisan-Seto Bridge with a continuous stiffening truss, each logarithmic decrement in the torsional and vertical modes is 0.030 to 0.038 and 0.040 to 0.10 , respectively. Although there is little difference in the logarithmic decrement in the torsional modes between these two types of bridges with stiffening truss, the logarithmic decrement in the first symmetric vertical mode of the Minami Bisan-Seto Bridge is 0.040 , which is much smaller than that of the Ohnaruto Bridge. The logarithmic decrement in the torsional and vertical modes of the Ohshima Bridge with stiffening box girder, is 0.017 to 0.038 and 0.015 to 0.16 , respectively, both of which are smaller than those of a truss structure. Logarithmic decrements in the first symmetric vertical, second symmetric vertical and first symmetric torsional modes are slightly lower than the design standards $(\delta=0.02)$. On the other hand, the logarithmic decrement in the first asymmetric vertical mode was larger in all bridges although still within the small amplitude region, indicating an outstanding dependence on amplitude.

(2) Influence of change in temperature

The Ohshima Bridge demonstrated a phe- nomenon in which the damping in the first asymmetric vertical mode decreased significantly as the temperature increased.

(3) Influence of center cable stay

A center cable stay sometimes increases the damping due to friction at the girder end to restrain the relative displacement of a girder and a cable. This phenomenon is conspicuous in the first asymmetrical vertical mode which produces a larger longitudinal displacement.

(4) Influence of wind velocity

The changes in aerodynamic damping accompanied by the changes in wind velocity generally can be estimated by the simplified quasi-steady calculation using the aerodynamic coefficient obtained by the wind tunnel test.

\section{( 2 ) Modeling in analysis of vibration}

i ) Boundary condition of stiffening girder end

In the first asymmetric vertical mode, restraining the longitudinal displacement of a girder end increased the frequency by $19 \%$ in the Ohnaruto Bridge, $37 \%$ in the Ohshima Bridge and $11 \%$ in the Minami Bisan-Seto Bridge. The dominant frequency under the ambient vibration is close to the calculated one when the girder end is restrained.

ii ) Rigidity of stiffening girder

The calculated natural frequency of a suspension bridge with a stiffening box girder is in good agreement with the measured one because the rigidity of the box girder can be appropriately estimated. However, in the case of a stiffening truss girder, the rigidity differs considerably according to how the rigidity of a truss as well as the floor structure is evaluated.

(1) Flexural rigidity of stiffening truss

It is assumed that a floor structure contributes to the flexural rigidity of a stiffening girder under small vibration. Assuming the floor structure is composited with the main structure, the natural frequency of the vertical modes increases by 5 to $17 \%$ in the Ohnaruto Bridge and 3 to $13 \%$ in the Minami Bisan-Seto Bridge.

(2) Torsional rigidity of stiffening truss

When the rigidity of floor structure is not considered, the natural frequency calculated in accordance with the Komatsu formula is smaller than the resonance frequency. When the rigidity of the floor structure is taken into consideration, however, the natural frequency is close to the dominant frequency. The natural frequency calculated in accordance with the Bleich formula is by 4 to $9 \%$ larger in the Ohnaruto Bridge and 5 to $10 \%$ larger in the Minami Bisan-Seto Bridge compared with that by the Komatsu formula.

In any case, in actual suspension bridge, the contribution of the floor structure to rigidity and 
the restraint of the girder end exist, therefore it can be concluded that suspension bridges exhibit the difference in vibrational characteristics depending on amplitudes in vibration. Moreover, wind or temperature of bridge body affect the vibrational characteristics in some structural systems or some modes. Therefore, in modeling the structural system for vibrational analyses and conducting vibration tests on actual bridges, careful consideration for the differences in vibrational characteristics between the small amplitude region and the significant amplitude region, considered a problem when designing the resistance to wind, and for the test conditions, must be mode beforehand.

\section{ACKNOWLEDGEMENTS}

The authors would like to thank the staff in the Honshu-Shikoku Bridge Authority and the Joint Ventures of construction for their cooperation and assistance. We also received suggestion and advice from the members of the Honshu-Shikoku Bridge Wind Resistance Committee, for which we are grateful.

\section{REFERENCES}

1) The Honshu-Shikoku Bridge Authority : Wind resistance design code for the Honshu-Shikoku Bridge, (1976), Bridge and Offshore Engineering Association, April 1978 (in Japanese).

2) The Honshu-Shikoku Bridge Authority : Wind tunnel test manual for Honshu-Shikoku Bridge, (1980), Bridge and Offshore Engineering Association, June 1980 (in Japanese).

3) H. Yamaguchi, M. Tatsumi and T. Miyata : Gravitational stiffness in tortional oscillation of suspension bridges and its effect on natural frequency, Proceedings of Japan Society of Civil Engineers, No.410, October 1989 (in Japanese).

4) S. Komatsu, N. Nishimura : Thee-dimentional analysis of truss girders by the thin walled elastic beam theory, Proceedings of the Japan Society of Civil Engineers, No.238, June 1965 (in Japanese).

5) F. Bleich, et al. : The Mathematical Theory of Vibration in Suspension Bridges, Department of Commerce Bureau of Public Roads.

6) Ahmed M. Abdel-Ghaffar, et al. : Ambient Vibration of Golden Gate Bridge, Journal of Engineering Mechanics, ASCE, VOL.III, No.4, April 1985.

7) J.M.W. Brownjohn, et al. : Ambient Vibration Measurements of the Humber Suspension Bridge and Comparison with Calculated Characteristics, Proc. Instn. Civ. Engrs, Part 2, 1987, 83, Sept.

8) Y. Fukui, H. Hiratsuka, R. Kiyota and T. Murakami : Vibration test of suspension bridges with stiffening box girder, Journal of Structural Engineering, Vol.35A, March 1989 (in Japanese).

9) Haruki Akiyama : Full-Scale Vibration Tests, Bridge and Foundation Engineering, Vol.22, August 1988 (in Japanese).

10) I. Okauchi, M. Tatsumi and H. Akiyama : Full-Scale Vibration tests on Long-Span Bridges, Proceedings of 10th National Symposium on Wind Engineering, 1988 (in Japanese).

11) T. Miyata, H. Yamada, and M. Tatsumi : Optimization of numerical frame model of Suspension Bridges for Wind Resistant Design, Proceedings of 11th National Symposium on Wind Engineering, 1990 (in Japanese).

(Received November 6, 1990)

\section{長大吊橋の振動特性に関する実橋振動実験と考察 岡内功・宮田利雄 ·辰巳正明 ·清田錬次}

吊橋の耐風設計において重要な構造減衰は, 計算によって求めることは不可能であり, 実橋の測定デー夕の蓄積がきわめて重要となる．筆者らは，新たに低周波用の大型起振 機を開発し, 補剛トラス, 補剛箱析を有する実際の長大吊橋の構造減衰を大振幅の自由 振動から求めた. さらに, 実際の構造系の振動挙動を検証し, 微小振動域と而風設計上 問題とされる振動振幅域での振動特性の差異, 実橋振動実験における種々の実験条件の 得られた結果への影響を考察した. 